\title{
BONE REGENERATION AND SOCKET PRESERVATION USING BONE AUGMENTING MATERIALS (HISTOMORPHOMETERIC STUDY IN RABBITS)
}

\author{
Eman Khalil* and Maha Galal A. Omar**
}

\begin{abstract}
Background: The ultimate goal of periodontal therapy is the regeneration of tissues destroyed by periodontal disease Fibronectin belongs to a group of high molecular weight glycoproteins that exist on cell surfaces. It is known to play a role in cell-to-cell and cell-to-substrate adhesion, as well as an essential role in osseointegration due to its capacity to make osteoblasts attach to the extracellular matrix (ECM) components. Combination of Fibronectin and commercially available bone grafts may hold a promising potential of enhanced bone regeneration.
\end{abstract}

Objective: Comparison of the effect of fibronectin, Bovine-Derived Xenograft (BDX)and their combination for socket preservation through histologic and histomorphometric analysis.

Material and Method: Thirty six clinically healthy adult New Zealand white male rabbits, were used in this study. The animals were equally divided into three groups; I-control group (defect was left empty as control), II- bio group (bio- oss was applied on the socket ) and III-( Bio Fibro group) bone and fibronectin group( socket was filled with Bovine-Derived Xenograft Bio-Oss ${ }^{\circledR}$ with fibronectin). At 4 and eight weeks the animals were sacrificed. Bone regeneration among the three groups was evaluated through histologic and histomorphometric analysis.

Results: The most significant value of area percent of newly formed bone was observed in the (bone and fibronectin) group, then the fibronectin group, with the least amount recorded in the control group. The difference was extremely statistically significant $(\mathrm{p}<0.0001)$. The socket is almost filled with newly formed bone trabeculae with organized fibrous tissue in the fibronectin and bone group ( Bio Fibro group ) at eight weeks.

Conclusion: Fibronectin is a useful biomaterial for the enhancement of bone formation. Combination of fibronectin and bovine graft seems to lead significantly to favorable bone regeneration and could be efficaciously used in the socket preservation.

* Lecturer of Oral Medicine, Periodontology, and Oral Diagnosis, College of Oral and Dental Surgery, British University In Egypt (BUE), Egypt.

** Professor of Oral Medicine, Periodontology, and Oral Diagnosis, College of Dentistry, Princess Nourah Bint Abdulrahman University. Riyadh, Saudi Arabia. 


\section{INTRODUCTION}

Alveolar bone seems to play a vital role in providing support to the teeth, which are anchored to the bone by desmodontal fibers. The progressive alveolar bone resorption process occurs due to a loss of anatomic, biologic and mechanical factors. Mechanical stimulation of alveolar bone during mastication is crucial in keeping the teeth and underlying bone healthy. Tooth extraction leads to a common bone deficiency of ridge width and height of alveolar crest and reduces the possibility of placing screw titanium implants. ${ }^{(1)}$

Previous animal studies concluded that dimensional change had been reported in fresh extraction sockets. Even if teeth with a severe inflammatory state are extracted, bone resorption may be more aggressive, and alveolar bone destruction may influence the perfect placement of the dental implant. ${ }^{(2-4)}$

Xenogenous bone grafts (e.g., Bio-Oss ${ }^{\circledR}$ ) have long been used in the treatment of periodontal bone defects. Bovine-Derived Xenograft (BDX) (Bio-Oss $®$ ) has osteoconductive properties and high biocompatibility that undergoes chemical extraction process by which all organic components are removed maintaining the natural architecture of bone. Osteoconductive properties guarantee biochemical support that gives stabilization to the coagulum in the first healing phases and a scaffold for new bone in the later stages. ${ }^{(5)}$ Due to its remarkable similarity to human bone, it is readily incorporated into the natural modeling and remodeling process. ${ }^{(6)}$

Fibronectin belongs to a group of high molecular weight glycoproteins that exist on cell surfaces. It is found in connective tissues, basement membranes, and extracellular fluids, and is known to play a role in cell-to-cell and cell-to-substrate adhesion, as well as an essential role in osseointegration due to its capacity to make osteoblasts attach to ECM components. ${ }^{(7)}$
Fibronectin is also known to enhance gingival fibroblast attachment, which has beneficial effects on healing after implant surgery and during the maintenance phase by forming attachments between connective tissue and the epithelium, which can prevent inflammatory breakdown around the implant. ${ }^{(8,9)}$

\section{Aim}

To evaluate the bone regenerative capacity of fibronectin, Bovine-Derived Xenograft (BDX) and their combination in socket preservation through histologic and histomorphometric analysis in rabbits.

\section{MATERIAL AND METHOD}

\section{A-Experimental model}

This experiment was conducted on a total of thirty-Six New Zealand white mature male rabbits weighing $2.5-4 \mathrm{~kg}$. The animals were housed in separate cages in temperature - controlled rooms and were fed on standard food and had free access to tap water. The animals were cared for according to the guidelines of the local Ethics Committee of the Animal Research at the Faculty of Medicine, Cairo University, which approved the project before the beginning of the experiments.

\section{Surgical procedure}

Rabbits were anesthetized intramuscularly with a mixture of Xylazine (Chanazine, Chanelle Pharmaceuticals, Ireland) $5 \mathrm{mg} / \mathrm{kg}$ body weight and ketamine hydrochloride (Ketamine, Pharmazeutische Pröparate, Germany) $30 \mathrm{mg} / \mathrm{kg}$ body weight. The rabbits were then subjected to the lower left incisor extraction using lower anterior extraction forceps, and the socket was excavated and cleaned of any remnants. The coaptation of the mucosa after grafting of the socket was performed by mattress technique using coated Vicryl 4/0 (Ethicon, Edinburgh, UK). The extracted sockets 
( $\mathrm{n}=12$ for the group) were grafted according to prescribed conditions for each of the three groups: group I filled with a blood clot(control)., group II, Bio oss* and group III (Bio-Fibro)

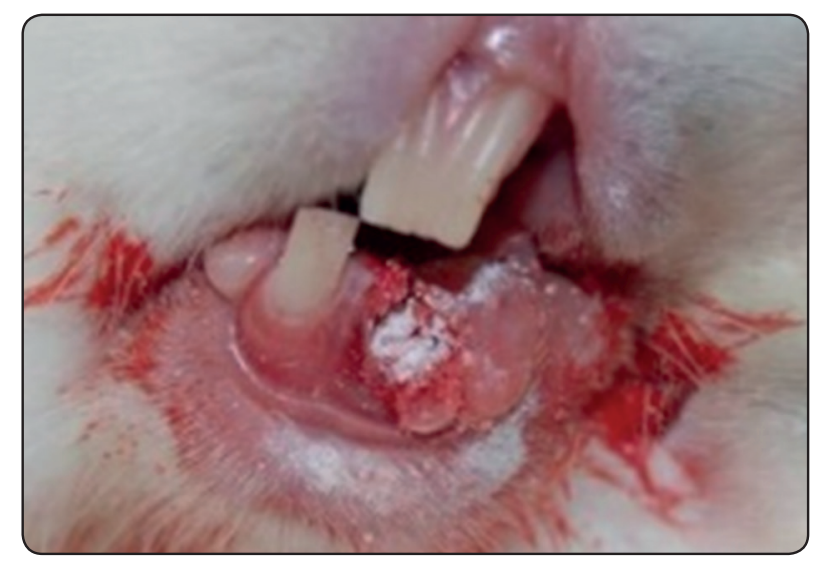

Fig (1) Bio-Oss was moistened with $0.5 \mathrm{ml}$ fibronectin

Bio Oss was moistened with $0.5 \mathrm{ml}$ fibronectin (Hayden, BioScience, Germany)** The rabbits were monitored closely every day up to 2 weeks postoperatively and placed on a soft ration diet to reduce the possibility of local trauma to the site of operation.

\section{Animal scarification}

Six rabbits from each group were sacrificed at 4 and eight weeks for histological using an intramuscular injection of $60 \mathrm{mg} / \mathrm{ml} / \mathrm{kg}$ body weight sodium phenobarbitone ( Phenobarbitone, Fawns \& McAllan Pty Ltd, Melbourne, Victoria).

\section{Histology}

The specimens from the operating region were obtained at sacrifice and were fixed in $10 \%$ buffered natural formaldehyde for 24 hours. They were then decalcified in ethylenediaminetetraacetic acid (EDTA) for 60 days. As decalcification was completed, the specimens were washed for 24 hours in running water to remove all traces of EDTA. The samples were gradually dehydrated in ascending concentrations of ethyl alcohol (50\%, 70\% and $90 \%)$ and two to three changes of absolute ethanol to ensure the replacement of water by alcohol. The specimens were passed from alcohol through two changes of xylene. The specimens were infiltrated with paraffin into a constant temperature furnace, at about $60^{\circ} \mathrm{C}$, until the xylene in the tissues was replaced by paraffin. Serial sections of $5 \mu \mathrm{m}$ were cut through the middle of the explant in the transverse direction in the mesiodistal plane representing most of the induced defect area. The specimens were mounted on the positively charged slides (opti plus), stained with Haematoxylin and Eosin (H\&E) stain and then examined under a light microscope.

\section{Measuring the area percent of bone trabeculae}

The area percent of bone trabeculae was estimated using Leica Quin 500 analyzer computer system, (Leica Microsystems, Switzerland). The cursor was used to outline the areas of bone trabeculae, which were then masked by a blue binary color that could be measured by the computer. The image analyzer is calibrated automatically to convert the measurement units (pixels) produced by the image analyzer program into actual micrometer units. The area percent of bone trabeculae was estimated in 5 different fields in each slide using magnification (x200). Mean values and standard deviation were calculated for each group.

Quantitative histomorphometric image analysis The image analysis was performed using a computer system Leica Quin 500, Image analyzer unit. Oral pathology department, Faculty of oral and dental medicine, Cairo University, to measure the thickness of newly formed bone trabeculae. ${ }^{(31,32)}$

\footnotetext{
* Xenograft, Geistlich Pharma, Wolhusen, Switzerland.

** Thermofisher Scientific, Waltham, Massachusetts, USA.
} 


\section{Statistical Analysis}

Numerical data were explored for normality by checking the distribution of data and using tests of normality (Kolmogorov-Smirnov and Shapiro-Wilk tests). Area \% data showed parametric distribution. Data were presented as mean, standard deviation (SD) and 95\% Confidence Interval for the mean (95\% CI) values.

Two-way Analysis of Variance (ANOVA) was used to study the effect of group, time and their interaction on mean area \%. Bonferroni's post-hoc test was used for pair-wise comparisons when the ANOVA test is significant.

The significance level was set at $\mathrm{P} \leq 0.05$. Statistical analysis was performed with IBM ${ }^{\circledR}$ SPSS $®$ Statistics Version 20 for Windows. ${ }^{\circledR}$ IBM Corporation, NY, USA. ® SPSS, Inc., an IBM Company.

\section{RESULTS}

\section{Two-way ANOVA results}

The results showed that group (regardless of time), time (regardless of group) as well as the interaction between the two variables had a statistically significant effect on mean area $\%$. Since the interaction between the variables is statistically significant, so the variables are dependent upon each other.

\section{Effect of the group regardless of time}

Regardless of time; there was a statistically significant difference between the groups (P-value $<0.001$, Effect size $=0.988$ ). Pair-wise comparisons between the groups revealed that Bio - Fibro group showed the statistically significantly highest mean area \%. Bio group showed statistically significantly lower mean area \%. Control group showed the statistically significantly lowest mean area $\%$.

TABLE (1). Two-way ANOVA results for the effect of different variables on mean area $\%$

\begin{tabular}{|c|c|c|c|c|c|c|}
\hline Source of variation & $\begin{array}{c}\text { Type III Sum } \\
\text { of Squares }\end{array}$ & df & Mean Square & $F$-value & $P$-value & $\begin{array}{c}\text { Effect size (Partial } \\
\text { eta squared) }\end{array}$ \\
\hline Group & 11814.692 & 2 & 5907.346 & 1238.501 & $<0.001^{*}$ & 0.988 \\
\hline Time & 4863.87 & 1 & 4863.87 & 1019.732 & $<0.001^{*}$ & 0.970 \\
\hline Group x Time interaction & 298.092 & 2 & 149.046 & 31.248 & $<0.001^{*}$ & 0.668 \\
\hline
\end{tabular}

$d f:$ degrees of freedom $=(n-1), *$ : Significant at $P \leq 0.05$

TABLE (2) The mean, standard deviation (SD), 95\% Confidence Interval values and results of two-way ANOVA test for comparison between area $\%$ of the three groups regardless of time

\begin{tabular}{|c|c|c|c|c|c|c|c|}
\hline \multicolumn{2}{|c|}{ Control } & \multicolumn{2}{c|}{ Bio } & \multicolumn{2}{c|}{ Bio - Fibro } & \multirow{2}{*}{ P-value } & $\begin{array}{c}\text { Effect size (Partial } \\
\text { eta squared) }\end{array}$ \\
\cline { 1 - 5 } Mean (SD) & $95 \%$ CI & Mean (SD) & $95 \%$ CI & Mean (SD) & $95 \%$ CI & \multirow{2}{*}{0.988} \\
\hline $36.5(16.1)^{\mathrm{C}}$ & $35.2-37.8$ & $48.9(11.3)^{\mathrm{B}}$ & $48.5-50.9$ & $79.8(9.1)^{\mathrm{A}}$ & $78.5-81$ & $<0.001^{*}$ & \\
\hline
\end{tabular}

*: Significant at $P \leq 0.05$, Different superscripts are statistically significantly different 


\section{Effect of time irrespective of the group}

Irrespective of the group; there was a statistically significant difference between the two follow up times (P-value $<0.001$, Effect size $=0.970$ ). Pairwise comparisons between the periods revealed that four weeks period showed a statistically significantly lower mean area $\%$ than eight weeks period.

After four weeks; there was a statistically significant difference between the groups (P-value $<0.001$, Effect size $=0.981)$. Pair-wise comparisons between the groups revealed that Bio - Fibro group showed the statistically significantly highest mean area $\%$. Bio group showed statistically significantly lower mean area \%. Control group showed the statistically significantly lowest mean area $\%$.

After eight weeks; there was a statistically significant difference between the groups (P-value $<0.001$, Effect size $=0.967$ ). Pair-wise comparisons between the groups revealed that Bio - Fibro group showed the statistically significantly highest mean area $\%$. Bio group showed statistically significantly lower mean area \%. Control group showed the statistically significantly lowest mean area $\%$.

In Control group; there was a statistically significant difference between the two follow up times (P-value $<0.001$, Effect size $=0.950$ ). Pairwise comparisons between the periods revealed that four weeks period showed a statistically significantly lower mean area $\%$ than eight weeks period.

In Bio group; there was a statistically significant difference between the two follow up times (P-value $<0.001$, Effect size $=0.909$ ). Pair-wise comparisons between the periods revealed that four weeks period showed a statistically significantly lower mean area $\%$ than eight weeks period.

In Bio - Fibro group; there was a statistically significant difference between the two follow up times (P-value $<0.001$, Effect size $=0.852$ ). Pairwise comparisons between the periods revealed that four weeks period showed a statistically significantly lower mean area $\%$ than eight weeks period.

TABLE (3) The mean, standard deviation (SD), 95\% Confidence Interval values and results of two-way ANOVA test for comparison between area $\%$ at the two follow up times regardless of group

\begin{tabular}{|c|c|c|c|c|c|}
\hline \multicolumn{2}{|c|}{ Four weeks } & \multicolumn{2}{c|}{ Eight weeks } & \multirow{2}{*}{ P-value } & $\begin{array}{c}\text { Effect size (Partial } \\
\text { eta squared) }\end{array}$ \\
\cline { 1 - 3 } Mean (SD) & $95 \%$ CI & Mean (SD) & $95 \%$ CI & & 0.970 \\
\hline $43.6(20.8)$ & $42.8-44.9$ & $66.8(16.2)$ & $65.8-67.9$ & $<0.001 *$ & 0 \\
\hline
\end{tabular}

*: Significant at $P \leq 0.05$

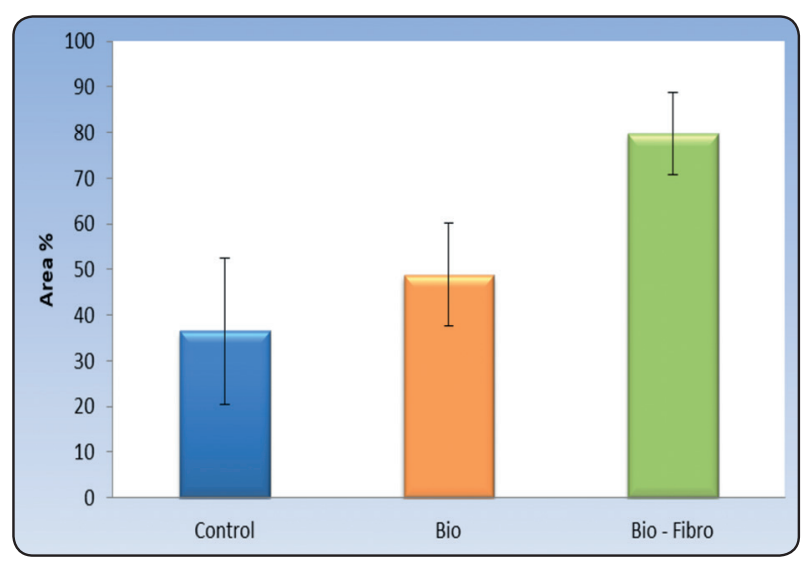

Fig. (2). Bar chart representing mean and standard deviation values for area $\%$ of the three groups regardless of time

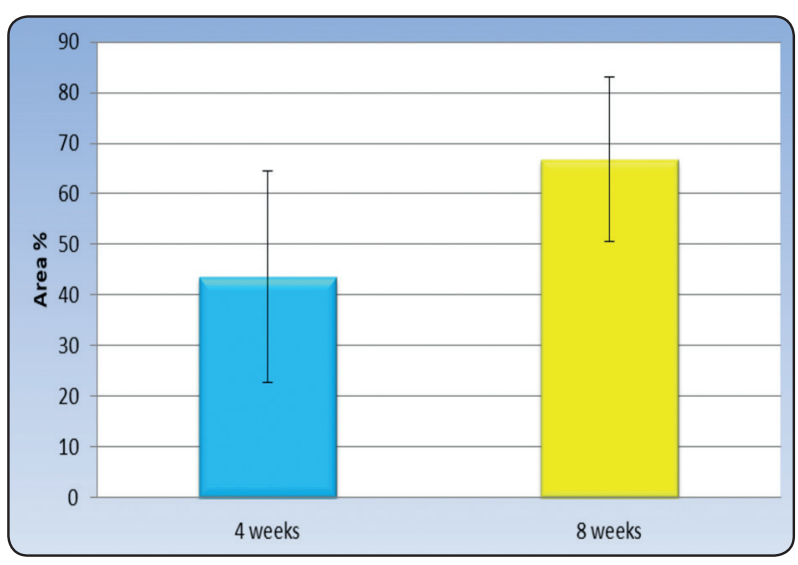

Fig. (3). Bar chart representing mean and standard deviation values for area $\%$ at the two follow up periods regardless of group interactions on area $\%$ 
TABLE (4) The mean, standard deviation (SD), 95\% Confidence Interval values and results of two-way ANOVA test for comparison between area $\%$ with different interactions

\begin{tabular}{|c|c|c|c|c|c|c|c|c|}
\hline \multirow{2}{*}{ Time } & \multicolumn{2}{|c|}{ Control } & \multicolumn{2}{|c|}{ Bio } & \multicolumn{2}{|c|}{ Bio - Fibro } & \multirow{2}{*}{$\begin{array}{c}P \text {-value } \\
\text { (Between } \\
\text { groups) }\end{array}$} & \multirow{2}{*}{$\begin{array}{c}\text { Effect size } \\
\text { (Partial eta } \\
\text { squared) }\end{array}$} \\
\hline & Mean (SD) & $95 \% \mathrm{CI}$ & Mean (SD) & $95 \% \mathrm{CI}$ & Mean (SD) & $95 \% \mathrm{CI}$ & & \\
\hline 4 weeks & $21.2(1.7)^{\mathrm{C}}$ & $19.4-23$ & $39(1.7)^{\text {в }}$ & $37.3-40.7$ & $71.3(0.9)^{\mathrm{A}}$ & $69.5-73.1$ & $<0.001 *$ & 0.981 \\
\hline 8 weeks & $51.9(1.8)^{\mathrm{C}}$ & $50.1-53.7$ & $60.4(3.3)^{\mathrm{B}}$ & $58.6-62.2$ & $88.2(2.9)^{\mathrm{A}}$ & $86.4-90$ & $<0.001 *$ & 0.967 \\
\hline $\begin{array}{c}P \text {-value } \\
\text { (Between times) }\end{array}$ & \multicolumn{2}{|c|}{$<0.001 *$} & \multicolumn{2}{|c|}{$<0.001 *$} & \multicolumn{2}{|c|}{$<0.001 *$} & & \\
\hline $\begin{array}{c}\text { Effect size } \\
\text { (Partial eta } \\
\text { squared) }\end{array}$ & \multicolumn{2}{|c|}{0.950} & \multicolumn{2}{|c|}{0.909} & \multicolumn{2}{|c|}{0.852} & & \\
\hline
\end{tabular}

*: Significant at $P \leq 0.05$, Different superscripts in the same row are statistically significantly different

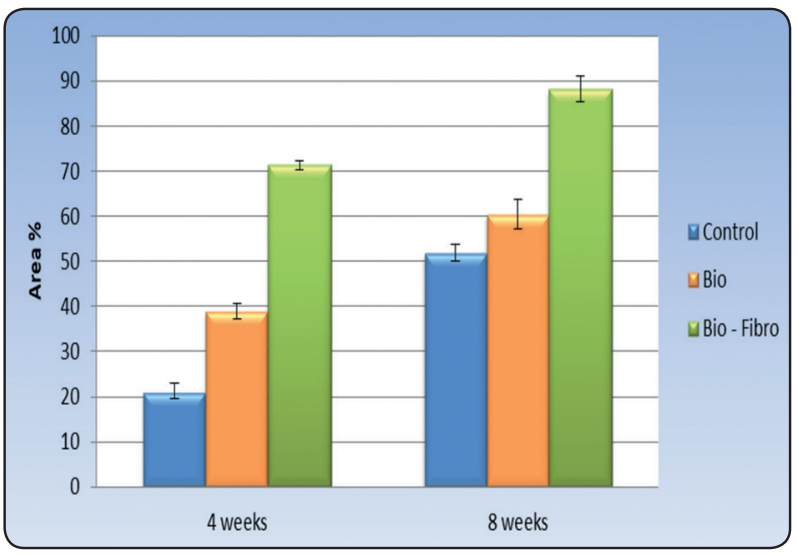

Fig. (4). Bar chart representing mean and standard deviation values for area $\%$ with different interactions of variables

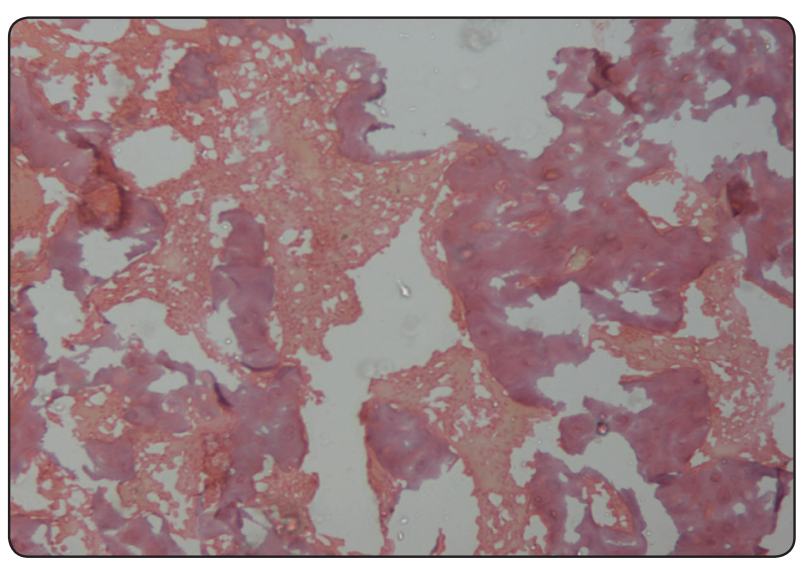

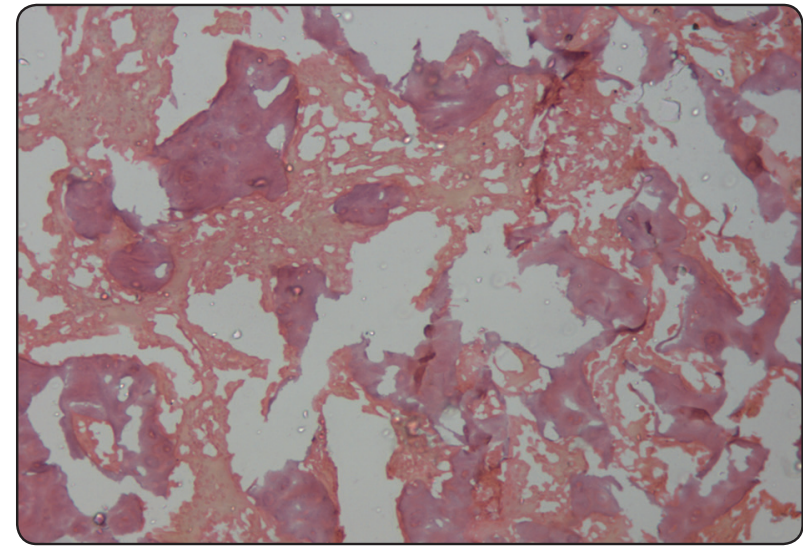

Fig. (5) C4 x200 Photomicrograph of the control group after four weeks showing few haphazardly arranged small irregular shaped bone trabeculae occupying a little of the granulation tissue ( $\mathrm{H}$ and $\mathrm{E} \times 200)$

Fig (6) C8 x200 Photomicrograph of the control group after eight-week showing large irregular shaped bone trabeculae occupying a large area of the granulation tissue (H and E x200) 
By observing histological sections of nonimplanted sockets of the control group, low osteoid activity was found, while fibrous connective tissue was abundant in the middle of the defects. Osteoid formation was not a characteristic finding. After, four, and eight weeks of implantation of tested materials, low osteoid activity was observed, while fibrous connective tissue was abundant in the middle

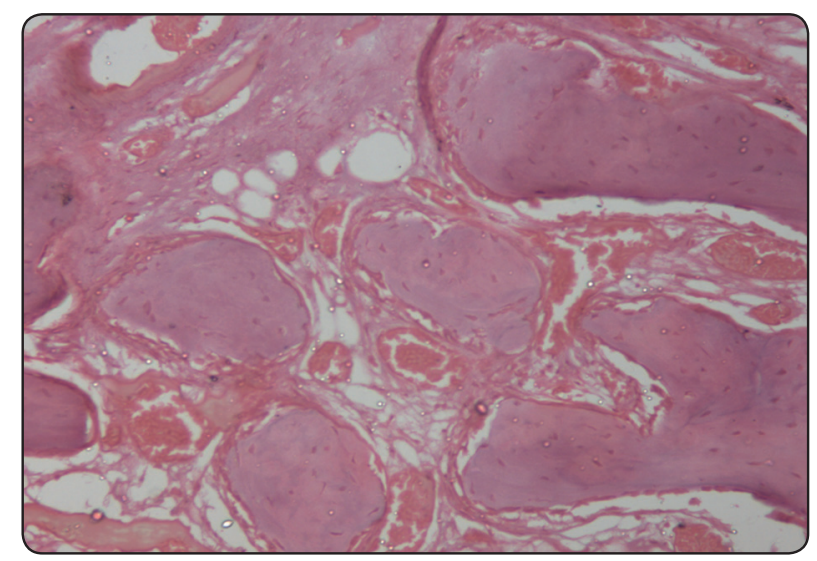

Fig (7) Bio 4 x200 Photomicrograph of the biotreated group after four week showing many small regular shaped and uniform bone trabeculae enclosing osteocytes and showing osteoblastic rimming occupying a large area of the granulation tissue. (H and E x200)

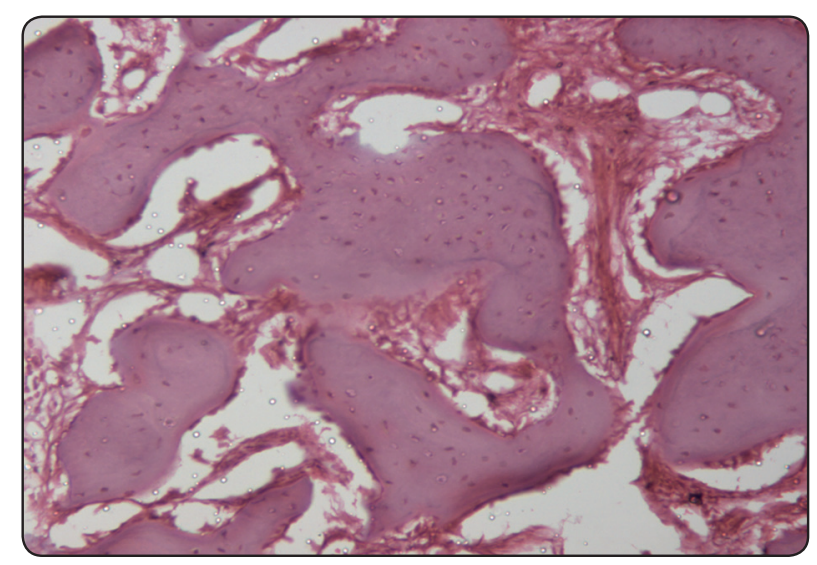

Fig. (9) Bio fibro 4x200 Photomicrograph of bio fibro treated group after four weeks showing large, well-formed interconnecting bone trabeculae enclosing osteocytes and showing osteoblastic rimming occupying most of the area of the granulation tissue( $\mathrm{H}$ and $\mathrm{E} \times 200)$ of the defects. Osteoid tissue could be seen in the defect cavity after eight weeks of implantation with -material that resulted in the gradual formation of new bone and was useful for ingrowth of the blood vessels and new tissues to defect. After eight weeks of implantation of material, it was replaced by the abundant new bone formation.

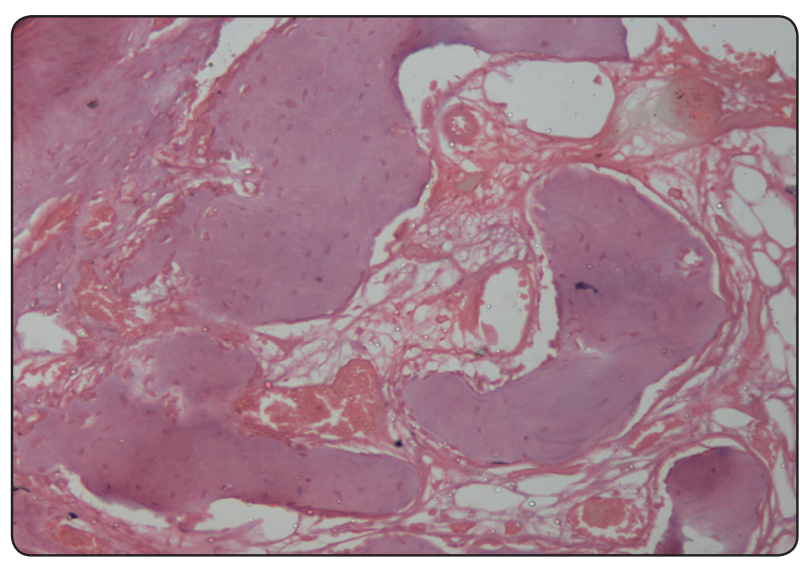

Fig. (8) Bio8 x200 Photomicrograph of the biotreated group after eight week showing many large regular shaped and uniform bone trabeculae enclosing osteocytes and showing osteoblastic rimming occupying most of the area of the granulation tissue $(\mathrm{H}$ and E x200)

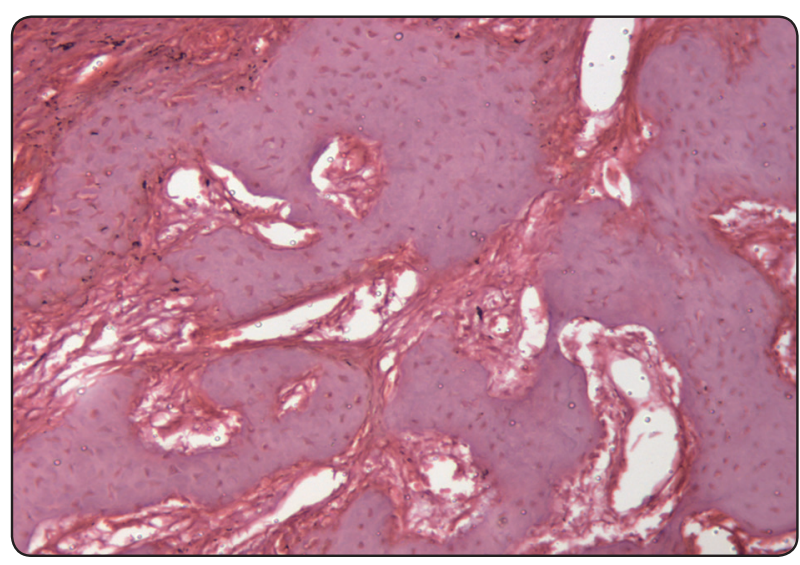

Fig. (10) Bio fibro 8x200 Photomicrograph of bio fibro treated group after eight w showing large, well-formed interconnected bone trabeculae enclosing osteocytes and showing osteoblastic rimming occupying almost all of the area of the granulation tissue(H and E x200) 


\section{DISCUSSION}

Loss of natural dentition leads to a reduction of physical stimulation of the alveolar bone which is irreversible, hence using materials that limit this resorption is essential for the preservation of bone after extraction.

The present study aimed to evaluate the bone regenerative capacity of Bio-Oss \& Fibronectin in socket preservation using histomorphometric analysis in rabbits.

Rabbit is the species with the least similarity to humans when it comes to histological bone structure and remodeling ${ }^{(10)}$. Despite that, rabbits are often used in skeletal research ${ }^{(11)}$ since they have certain advantages in other aspects. Aside from economic reasons, rabbits are majority laboratory animals because of their size, temperament and availability of genetically similar strains., New Zealand White rabbits were selected because of their short developmental period and their faster bone turnover than primates ${ }^{(12)}$. Unlike other mammals such as the rat, mouse and guinea pig, rabbits achieve skeletal maturity (closure of epiphyseal plates) shortly after reaching complete sexual development at approximately six months ${ }^{(12)}$, and they show significant intracortical remodeling ${ }^{(13)}$. Rabbit long bones generally consist of primary bone tissue (as reviewed by $9 \& 10)$ compared to the secondary of humans. Their bones also heal faster. Agrawal, C. M. (1998 Discuss that a dental implant placed in a rabbit long bone may only need six weeks to be osseointegrated whereas it takes 3-4 months in a human ${ }^{(14)}$. This can make it difficult to extrapolate results from rabbit studies to humans (as reviewed by (10).

Rabbits are easy to handle (as reviewed by (10), and it is possible to keep and observe many at the same time ${ }^{(15)}$. They are readily available and less expensive than larger animals (as explained by ${ }^{(16)}$. It is also convenient that rabbits develop and reach skeletal maturity fast. Skeletal growth in the New Zealand white rabbit is completed at 28 weeks of age $^{(17)}$.
The rabbit is an excellent model to start with for testing regenerative capacity before checking in a larger animal model (as reviewed by ${ }^{(10)}$.

Histomorphometric analysis was performed as a traditional gold standard for evaluation.

This technique is relatively standard in bone tissue formation assessment. It is a useful method for comparison to monitoring the bone healing pattern. This method allows for the comprehensive description of bone regeneration and provides a guideline for the planning of future pre-clinical and clinical studies. ${ }^{(18,19)}$

Our results showed that at four weeks the greatest mean area percentage was recorded in the bio-fibro group, whereas the lowest mean value was recorded in control. The same findings were also noted when comparing groups at eight weeks.

Comparing the three groups in the two different dates, the highest mean area percent was recorded in the bio-fibro group at eight weeks, whereas the lowest mean value was recorded in control at four weeks. This was in the line of histological findings, by observing histological sections of nonimplanted sockets of the control group, low osteoid activity was found, while fibrous connective tissue was abundant in the middle of the defects. Osteoid formation was not a characteristic finding. After, four, and eight weeks of implantation of tested materials, low osteoid activity was observed, while fibrous connective tissue was abundant in the middle of the defects. Osteoid tissue could be seen in the defect cavity after eight weeks of implantation with -material that resulted in the gradual formation of new bone and was useful for ingrowth of the blood vessels and new tissues to defect. After eight weeks of implantation of material, it was replaced by the abundant new bone formation

In the present study, through histomorphometric analysis, all treatment groups and at each of the experimental intervals, the mean area percentage 
of newly formed bone was more significant in the group BIO-FIBRO compared to BIO\& control groups. In both defects, the highest value of area percent of newly formed bone was observed in the (BIO-FIBRO) group, followed by the FIBRO group, then the CONTROL group, with the least value recorded in the control group. In all groups, the area percentage of newly formed bone increased by time, with the highest mean recorded at eight weeks. A hugely significant difference was detected in the all groups in 8 weeks. These findings were supported by the histological findings in which (BIO-FIBRO) group showed increase information of more organized bony trabecula than each alone.

The positive effects of BIO-OSS as a sole graft material was higher than the control group in the defects.

Nevertheless, in our results, improvement in bone formation was observed in BIO-FIBRO group than the BIO group in the socket defects during different observation periods. Osteoconductive properties of bovine bone guarantee biochemical support that gives stabilization to the coagulum in the first healing phases and a scaffold for new bone in the later stages. ${ }^{(5)}$

The maximum regenerative potential was reported in combined FIBRO and bovine xenograft (BIO-OSS) group than other groups postoperatively and during all observation periods.

The Fibronectin network is an essential factor for the differentiation, expression of physiological function, and survival of osteoblasts ${ }^{(20)}$. Fibronectin is identified as a target protein for bFGF signaling pathway in cultured osteoblast ${ }^{(21)}$.

In an agreement, our study showed that the highest mean area percentage that was recorded in Bio-Fibro group at eight weeks is significantly more than the control group in which the lowest mean value was recorded in 4 weeks

Biomimetic coating with fibronectin has been tested in previous studies ${ }^{[22-25]}$. It is believed that application of fibronectin to the implant surface can enhance the osseointegration of dental implants to the bone ${ }^{[22-25]}$. Fibronectin is one of the celladhesive proteins that can improve cell activity, initial cell attachment, and cell spreading, and it is actively involved in cytoskeletal reorganization and bone tissue formation, in part by regulating the survival of osteoblasts ${ }^{[26]}$.

Fibronectin is also known to enhance gingival fibroblast attachment, which has beneficial effects on healing after implant surgery and during the maintenance phase by forming attachments between connective tissue and the epithelium, which can prevent inflammatory breakdown around the implant. ${ }^{[27-30]}$.

Accordance to our results that explains it with the max area percentage of bone formation was recorded in Bio-Fibro group where the regenerative effect of Bio-Oss is augmented by application of fibronectin that was noticed in comparison with the group of Bio-OSS alone or Control.

In conclusion, Treatment of osteoblasts with bFGF increased membrane translocation of various isoforms of PKC, including $\alpha, \beta, \epsilon$, and $\delta$. However, treatment with antisense of various PKC isoforms demonstrated that $\alpha$ and $\beta$ isozymes play essential roles in the enhancement action of bFGF on Fn assembly, so the application of fibronectin to bone grafting material could enhance bone regenerative potentials help in socket preservation during the different observation period. ${ }^{33}$

\section{ACKNOWLEDGMENT}

I am grateful to all of those with whom I have had the pleasure to work during this research. Each of the members has provided me extensive personal and professional guidance and taught me a great deal about both scientific research and life in general. I would especially like to thank Dr. Nermin Raouf Amin, Assistant professor in oral and maxillofacial pathology, Cairo University. 


\section{REFERENCES}

1- Bodic F., Hamel L., Lerouxel E., Baslé M.F., Chappard D.: Bone loss and teeth. Joint Bone Spine. 2005, 72, 215-221.

2- Fickl S, Zuhr O, Wachtel H, Bolz W, Huerzeler M. Tissue alterations after tooth extraction with and without surgical trauma: a volumetric study in the beagle dog. J Clin Periodontol. 2008;35:356-363.

3- Elkarargy A. Alveolar sockets preservation using hydroxyapatite /beta-tricalcium phosphate with hyaluronic acid (histomorphometric study). J Am Sci. 2013;9:556-563.

4- Su Y, Tang J, Min S, et al. Alveolar ridge dimensional changes following ridge preservation procedure with novel devices: part3 - histological analysis in the non-human primate model. Clin Oral Implants Res. 2017;28:e252-e261.

5- Baldini, De Sanctis M, Ferrari (2011). Deporetinizedbovin bone in periodontal and implant surgery. Dental Materials. 27 (1) 61- 70.

6- Lekovic V V, Milinkovic II, Aleksic Z Z, Jankovic SS, Stankovic P P, Kenney E B EB, Camargo PM PM(2012). Platelet-rich fibrin and bovine porous bone mineral vs. platelet-rich fibrin in the treatment of intrabony periodontal defects.J Periodontal Res.47(4): 409-17.

7- Park JM, Koak JY, Jang JH, Han CH, Kim SK, Heo SJ. Osseointegration of anodized titanium implants coated with fibroblast growth factor-fibronectin (FGFFN) fusion protein. Int J Oral Maxillofac Implants 2006; 21:859-66.

8- doSerro AP, Fernandes AC, de Jesus Vieira Saramago B. Calcium phosphate deposition on titanium surfaces in the presence of fibronectin. J Biomed Mater Res. 2000;49:345-52. [PubMed]

9- Tamada Y, Ikada Y. Effect of preadsorbed proteins on cell adhesion to polymer surfaces. J Colloid Interface Sci. 1993;155:334-9.

10- Pearce, A. I., Richards, R. G., Milz, S., Schneider, E. \& Pearce, S. G. (2007) Animal models for implant biomaterial research in bone: a review. Eur Cell Mater 13, 1-10.

11- Neyt, J. G., Buckwalter, J.A. \& Carroll, N. C. (1998) Use of animal models in musculoskeletal research. Iowa Orthop J $18,118-23$

12- Gilsanz V, Roe TF, Gibbens DT, Schulz EE, Carlson ME, Gonzalez O, Boechat MI. (1988) Effect of sex steroids on peak bone density of growing rabbits. Am J Physiol 255: E416-E421.
13- Kimmel DB. (1996) Animal models for in vivo experimentation in osteoporosis research. In: Osteoporosis. Marcus R, Feldman D, Kelsey J (eds.). Academic Press, San Diego.pp. 671-690.

14- Wang, X., Mabrey, J. D. \& Agrawal, C. M. (1998) An interspecies comparison of bone fracture properties. Biomed Mater Eng 8, 1-9.

15- Martiniaková, M., Omelka, R., Chrenek, P., Ryban, L., Parkányi, V., Grosskopf, B., Vondráková, M., Bauerová, M. (2005) Changes if femoral bone tissue microstructure in transgenic rabbits. Folia Biol (Praha) 51(5), 140-4.

16- Albrektsson, T., Brånemark, P. I., Hansson, H. A., Lindström, J. (1981) Osseointegrated titanium implants. Requirements for ensuring a long-lasting, direct bone- to- implant anchorage in man. Acta Orthop Scand 52(2), 155-70.

17- Calasans-Maia, M. D., Monteiro, M. L., Ascoli F. O. \&Granjeiro, J. M. (2009) The rabbit as an animal model for experimental surgery. Acta Cir Bras 24, 325-8.

18- Mapara, M., Thomas, B. S. \& Bhat, K. M. (2012) Rabbit as an animal model for experimental research. Dent Res J (Isfahan) 9, 111-8

19- Masoud, I., Shapiro, F., Kent, R. \& Moses, A. (1986) A longitudinal study of the growth of the New Zealand white rabbit: cumulative and biweekly incremental growth rates for body length, body weight, femoral length, and tibial length. J Orthop Res 4, 221-31

20- Tejada, Ph.D.,1,2,* AniqDarr, Ph.D.,3 David T. Silliman, BA,1 Maria H.R. Magno, Ph.D.,3 Joseph C. Wenke, Ph.D.,4 Joachim Kohn, Ph.D.,3 and Pamela R. Brown Baer, MEd, DDS1,

21- Methods to Analyze Bone Regenerative Response to Different rhBMP-2 Doses in Rabbit Craniofacial Defects. TISSUE ENGINEERING: Part C Volume 20, Number 9, 2014

22- Globus RK, Doty SB, Lull JC, Holmuhamedov E, Humphries MJ, and Damsky CH (1998) Fibronectin is a survival factor for differentiated osteoblasts. J Cell Sci 111:1385-1393

23- Yang RS, Tang CH, Ling QD, Liu SH, and Fu WM (2002) Regulation of fibronectin fibrillogenesis by protein kinases in cultured rat osteoblasts.MolPharmacol 61:1163-1173.

24- Chen C, Lee IS, Zhang SM, Yang HC. Biomimetic apatite formation on calcium phosphate-coated titanium in Dulbecco's phosphate-buffered saline solution containing $\mathrm{CaCl}(2)$ with and without fibronectin. ActaBiomater 2010; 6:2274-81 
25- Hayakawa T, Yoshinari M, Nemoto K. Direct attachment of fibronectin to tresyl chloride-activated titanium. J Biomed Mater Res 2003;67:684-8.

26- Park JM, Koak JY, Jang JH, Han CH, Kim SK, Heo SJ. Osseointegration of anodized titanium implants coated with fibroblast growth factor-fibronectin (FGF-FN) fusion protein. Int J Oral Maxillofac Implants 2006;21:859-66

27- doSerro AP, Fernandes AC, de Jesus Vieira Saramago B. Calcium phosphate deposition on titanium surfaces in the presence of fibronectin. J Biomed Mater Res 2000;49: 345-52.

28- Weiss RE, Reddi AH.Synthesis and localization of fibronectin during collagenous matrix-mesenchymal cell interaction and differentiation of cartilage and bone in vivo. Proc Natl AcadSci U S A 1980;77:2074-8.

29- Malmstrom HS, Fritz ME, Timmis DP, Van Dyke TE. Osseointegrated implant treatment of a patient with rap- idly progressive periodontitis. A case report. J Periodontol 1990;61:300-4.

30- Mombelli A, Lang NP. The diagnosis and treatment of periimplantitis.Periodontol 2000 1998;17:63-76.

31- Wang, H.-L., Kiyonobu, K., \& Neiva, R. F. (2004). Socket augmentation: rationale and technique. Implant Dentistry, 13(4), 286-296.

32- Chandna, S., Kaur, K., Kaur, N., \& Manocha, A. (2015). Socket augmentation. Journal of the International Clinical Dental Research Organization, 7(3), 73-80. http://doi. org/10.4103/2231-0754.172937

33- Tang, C.-H., Yang, R.-S., Huang, T.-H., Liu, S.-H., \& Fu, W.M. (2004). Enhancement of Fibronectin Fibrillogenesis and Bone Formation by Basic Fibroblast Growth Factor via Protein Kinase C-Dependent Pathway in Rat Osteoblasts. Molecular Pharmacology, 66(3), 440 LP-449. Retrieved from http:// molpharm.aspetjournals.org/content/66/3/440.abstract 